\title{
"Top of the Basilar" Occlusion Causing Bilateral Internuclear Ophthalmoplegia
}

\author{
Daisuke Arai and Masashi Nakajima
}

Key words: basilar artery, internuclear ophthalmoplegia, midbrain infarction

(Intern Med 50: 527-528, 2011)

(DOI: 10.2169/internalmedicine.50.4716)
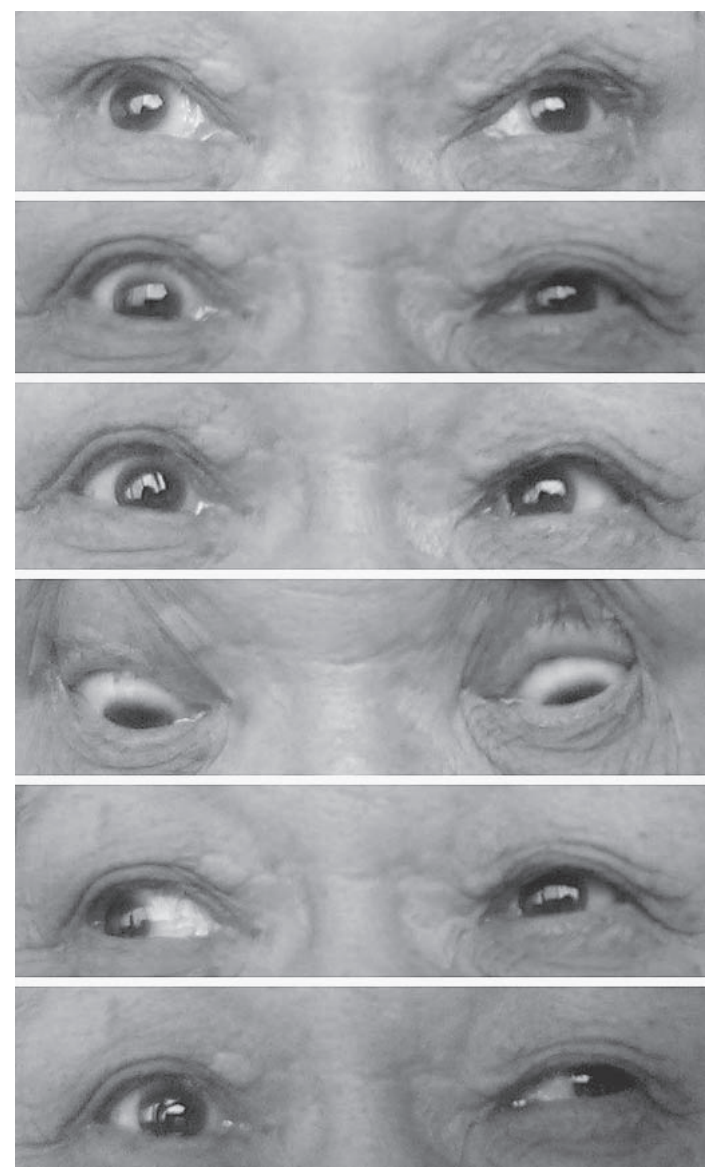

Picture 1.

Recent advances in non-invasive imaging techniques of posterior circulation have demonstrated that basilar artery occlusion may have a wide spectrum of clinical presentations (1). A 79-year-old woman with chronic atrial fibrillation presented with sudden onset vertigo and diplopia. Positions of upward gaze, forward gaze, convergence, downward gaze, right gaze, and left gaze are shown from top to bottom
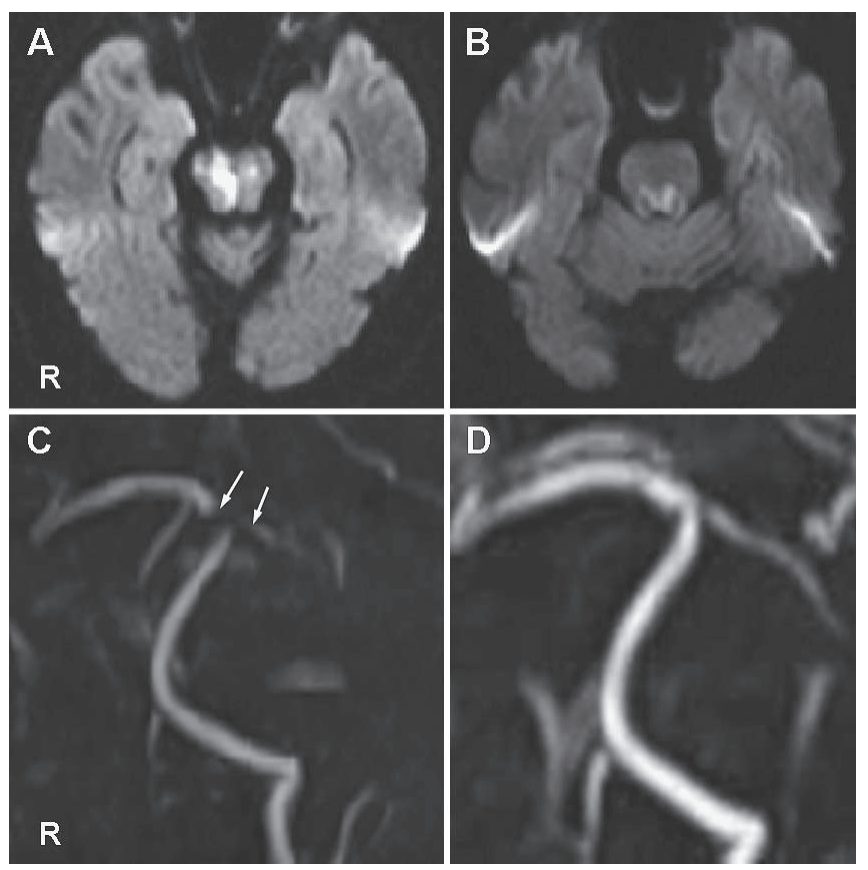

Picture 2.

(Picture 1). There was paresis of adduction associated with abducting nystagmus of both eyes. Upward gaze was limited, but downgaze and convergence were preserved. Pupillary and levator function were normal. She also had bilateral limb ataxia. Diffusion-weighted magnetic resonance (MR) imaging showed an acute infarction in the right paramedian territory at the level of the inferior colliculus (Picture 2A) and in the bilateral paramedian tegmentum at the level of the isthmus rhombencephali (Picture 2B). MR angiographic images demonstrated a lack of blood flow at the top of the basilar artery and patent proximal posterior cerebral arteries (arrows) (Picture 2C), and later recanalization of the basilar artery (Picture 2D). The vascular etiology of a bilateral internuclear ophthalmoplegia (INO) is an occlusion of a uni- 
lateral paramedian pontine artery that may supply the medial longitudinal fasciculus bilaterally (2). A bilateral paramedian midbrain infarction due to a "top of the basilar" artery occlusion is another vascular etiology of bilateral INO.

The authors state that they have no Conflict of Interest (COI).

\section{References}

1. Voetsch B, DeWitt D, Pessin MS, Caplan LR. Basilar artery occlusive disease in the New England Medical Center Posterior Circulation Registry. Arch Neurol 61: 496-504, 2004.

2. Fisher CM. Neuroanatomic evidence to explain why bilateral internuclear ophthalmoplegia may result from occlusion of a unilateral pontine branch artery. J Neuroophthalmol 24: 39-41, 2004.

\footnotetext{
(C) 2011 The Japanese Society of Internal Medicine http://www.naika.or.jp/imindex.html
} 